\title{
Columnar Aerosol Extinction Characteristics: Measurements from a Free-Tropospheric Observatory in Western-Himalayas
}

\author{
Mukunda M Gogoi ${ }^{1 *}$, Jai Prakash Chaubey ${ }^{1}$, V Sreekanth ${ }^{1}$, Sobhan Kumar Kompalli ${ }^{1}$, \\ S Suresh Babu ${ }^{1}$, Tushar P Prabhu ${ }^{2}$ and K Krishna Moorthy ${ }^{1}$ \\ ${ }^{1}$ Space Physics Laboratory, Vikram Sarabhai Space Centre, Trivandrum 695 022, India \\ ${ }^{2}$ Indian Institute of Astrophysics, Bangalore 560 034, India
}

\begin{abstract}
Continuous measurements of spectral aerosol optical depths (AOD) were made over a very high altitude aerosol observatory at Hanle $\left(32.76^{\circ} \mathrm{N}, 78.95^{\circ} \mathrm{E}, 4520 \mathrm{~m} \mathrm{amsl}\right)$, during the summer and autumn of 2009 and 2010, by using a 10-channel multi-wavelength radiometer (MWR). The results depicted very low values of AOD (with a mean for the measurement period as $\sim 0.071 \pm 0.003$ at $500 \mathrm{~nm}$ ), but with a spectral dependence that changed with the months from $\sim 0.8$ to 1.3 , with a mean value of $\sim 1.01 \pm 0.06$. The AODs though were in general comparable to those seen over pristine Antarctic environments, are quite significant when we consider the altitude of the station. The details are presented.
\end{abstract}

\section{Introduction}

Spectral aerosol optical depth (AOD), the column integrated aerosol extinction (due to scattering and absorption), is the parameter with greatest influence on the aerosol direct radiative forcing. Moreover, characterization of AOD is essential in understanding the aerosol-cloud interactions, atmospheric remote sensing and global aerosol modeling. However, the accurate estimation of AOD at different geographical environments is indeed a challenging task, especially over the very high altitude, remote locations, where the pristine and free conditions are favorable for studying background aerosol features against which polluted and urban environments could be compared. Interestingly, the far remote locations are now not free from major anthropogenic influences. Recent studies indicate new insight into the aerosol transport mechanisms from dust and pollution sources to the Tibetan and Himalayan regions (Marcq et al., 2010). The role of transported aerosols from India and Pakistan influencing the local energy budget in the Himalayas have also been reported by several recent investigators (e.g., Carrico et al., 2003). However, large data-gap still persists in fully understanding the aerosol features and relevant transport mechanisms over various high altitude locations. Viewed in the above perspectives and with a view to understanding the role of the regional warming due to elevated aerosol layers on the weather and climate of Indian Subcontinent, a high altitude aerosol observatory has been established at Hanle $\left(32.76^{\circ} \mathrm{N}, 78.95^{\circ} \mathrm{E}\right)$ in western Himalayan, at an altitude of $\sim 4520 \mathrm{~m}$ above mean sea level.

Continuous measurements of spectral aerosol optical depths (AOD) are being made over Hanle, by using a 10-channel multi-wavelength radiometer (MWR) since August 2009. The database obtained till December 2010 are used in the present analysis to infer knowledge on the columnar abundance of aerosols and their extinction properties. Being a part of ARFI network observatories, which has now grown to 34 stations across the length and breadth of the country, 
long-term comprehensive measurements of AOD at Hanle will contribute to the regional aerosol database for climate impact assessment.

\section{Site description and general meteorology}

The geographic location of Hanle is shown in Fig.1, a village in the highest plateau of transHimalayan region, to the west of the Tibetan plateau. The measurements were carried out from the premises of the Himalayan Chandra Telescope site of the Indian Institute of Astrophysics, atop Mt Saraswati.

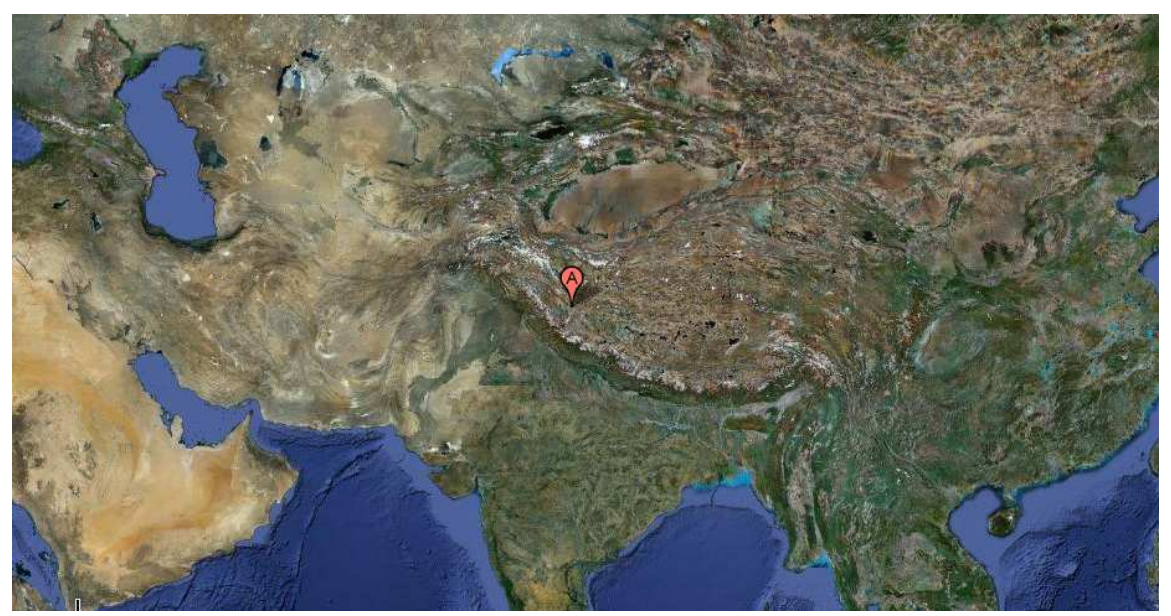

Figure 1: Geographic location of Hanle in western Himalayan

Collocated a high-resolution (one second) automatic weather station (AWS) data were used to infer meteorological information at Hanle. The monthly mean temperature exhibited a seasonal behavior characterized by a maximum during the summer (June-August) period, the highest values being measured in July (even above $10^{\circ} \mathrm{C}$ ). Lower values of temperature were recorded during winter (December-February, the lowest $\left(<-7^{\circ} \mathrm{C}\right)$ being observed in December). The relative humidity $(\mathrm{RH})$ at Hanle also followed nearly similar monthly pattern as that of temperature, with very low values in November/December and highest in the month of August $($ mean $=62 \pm 12 \%)$. The lower values of RH $(<40 \%)$ persisting during most part of the year indicate the dry atmosphere (mean $\mathrm{RH}=31.92 \pm 11.96$ ) over Hanle. During the investigated period, monthly mean values of wind speed (WS) varied from 3 to $6 \mathrm{~ms}-1$, while the daily mean values varied much larger from 1 to $15 \mathrm{~ms}-1$. Thus, the measurement site appears to be an extremely windy location. The wind direction has been predominantly southwesterly during the study period.

\section{Instrument details}

The ground based Multi Wavelength solar Radiometer (MWR) (Moorthy et al., 2007) follows the principle of filter wheel radiometry to obtain the spectral AOD at 10-wavelength bands centered at 380, 400, 450, 500, 600, 650, 750, 850, 935 and $1025 \mathrm{~nm}$. Following the Langley plot technique, AODs were estimated at each wavelength from the continuous operation of the MWR on all clear and partly clear days when unobstructed solar visibility (for the portion of the sky 
with angular diameter of $\sim 10^{\circ}$ with the sun at the center) was available for $>3$ hour a day. The instrument operates in a fully automatic mode employing a passive equatorial mount and the continuous measurements of direct solar flux are made at regular intervals of 2 min over the entire wavelength range. Following Lambert-Bouguer-Beer law, the continuous measurements of output voltage $\left(V_{\lambda}\right)$, made as a function of time (solar zenith angle) during a day, yields a linear relation of $\log \left(V_{\lambda}\right)$ with relative airmass $(m)$. A plot of $\log \left(V_{\lambda}\right)$ against $m$ show the points lying very close to, or on a straight line, the slope of which is the measure of the total optical depth $\tau_{\lambda}$ and the intercept (called Langley intercept) extrapolated to meet the ordinate (for $m=0$ ) is representative of $F_{0 \lambda}$ (incident solar flux at the top of the atmosphere), which can be used as a self-calibration for the radiometer.

Based on the consistency of the Langley intercept, the MWR data during the summer and autumn of 2009 and 2010 were analyzed to obtain the temporal features of aerosols properties at Hanle. The data collected during any day are considered as a single set if they span only 3-4 h and the AOD is considered as mean for the day. However, on days when the Langley intercept showed two different slopes during FN and AN part of the day (when the data span over more than $2 \mathrm{~h}$ in the FN and AN), then the data are considered as two separate sets and AODs are deduced for each set separately.

\section{Results and Discussions}

\section{Temporal variation of $A O D$}

The clear sky measurements of direct solar flux at Hanle depicted, in general, very low values of spectral AOD (denoted by $\tau_{\mathrm{p} \lambda}$ ). The temporal variation of the monthly mean AOD at $500 \mathrm{~nm}$ being shown in Fig.2, where the vertical bars through the mean are the standard errors, indicates that the values of AOD varied between $\sim 0.05 \pm 0.004$ and $0.09 \pm 0.01$, with a mean value of $\sim$ $0.071 \pm 0.003$ at $500 \mathrm{~nm}$ for the measurement period. The time series of the daily mean AOD, superposed with monthly mean values in Fig.2, also indicates that the occurrences of higher values of AOD (>0.1) were relatively less, which may be due to either the appearance of thin cirrus clouds out of the normal human visibility or the loading of the atmosphere due to in situ productions as well as advection component. The AODs though were in general comparable to those seen over pristine Antarctic environments, are quite significant when we consider the altitude of the station.

Similar studies from different high altitude station also reveal the consistency of aerosol extinctions at the background locations. An annual mean value of AOD $~ 0.05$ at $500 \mathrm{~nm}$ was reported by Cong et al. (2009) over an AERONET station Nam Co $(4720 \mathrm{~m}$ amsl) in central Tibetan Plateau. An annual mean value of $~ 0.02$ was reported for Mauna Loa (3397 m amsl), with a seasonal peak of 0.033 during February-March (Holben et al., 2001). Six et al. (2005) have reported the value of AOD as low as 0.02 at $440 \mathrm{~nm}$ over Dome C in Antarctica. From the continuous operation of CIMEL sun-photometer at a very high altitude station in Nepal Climate Observatory Pyramid (NCOP, $5079 \mathrm{~m}$ amsl), Gobbi et al. (2010) reported that the seasonal mean values of AOD varied between 0.04 and 0.08. Over the foothill regions of Himalayan, it was reported that the value of AOD varied between 0.059 and 0.157 over Nainital $(1950 \mathrm{~m}$ amsl, Sagar et al., 2004) and 0.24 and 0.27 over Kullu (1154 m amsl, Kuniyal et al., 2009). 


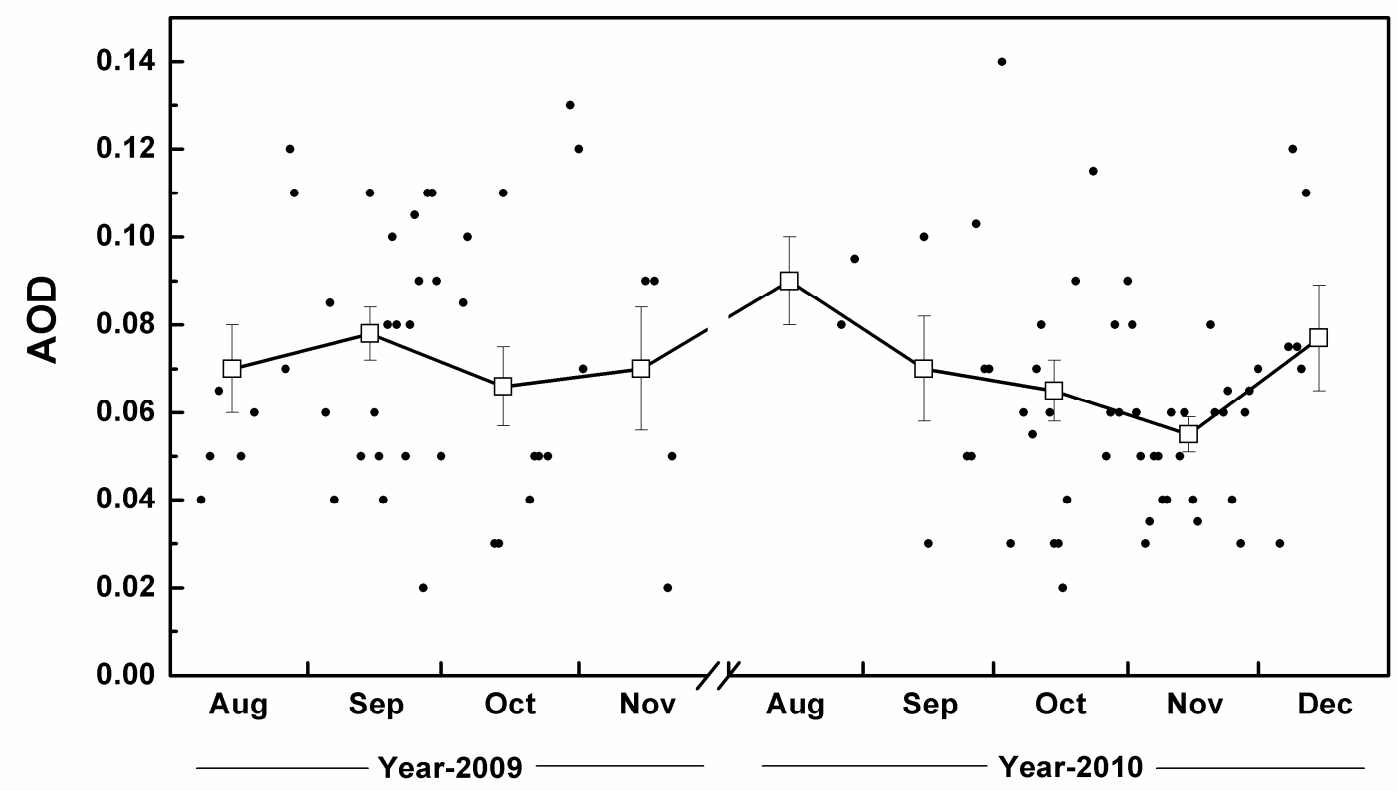

Figure 2: Temporal variation of monthly mean AOD at $500 \mathrm{~nm}$

\section{Spectral variation of $A O D$ and Angstrom exponents}

The spectral variation of monthly mean AODs are examined by plotting the $\tau_{\mathrm{p} \lambda}$ values as a function of wavelength $(\lambda)$, shown in Fig.3. In general, the wavelength dependence of $\tau_{\mathrm{p} \lambda}$ remains nearly similar in all the months, which decrease sharply with increase in wavelength up to 850 $\mathrm{nm}$ and then increases slowly towards the NIR bands. The observed spectral features of AOD are thus indicative of the size distribution of aerosols, which can be inferred in the simplest way from the Angstrom wavelength exponent $\alpha$. Following Angstrom (1961), the wavelength variation of $\tau_{\mathrm{p} \lambda}$ can be expressed as

$$
\tau_{p \lambda}=\beta \lambda^{-\alpha}
$$

where $\beta$ is the Angstrom turbidity coefficient, which numerically equal to $\tau_{\mathrm{p} \lambda}$ at $\lambda=1 \mu \mathrm{m}$.

In the present study, $\tau_{\mathrm{p} \lambda}$ values of individual sets of observations were examined for their agreement with equation 1 , evolving a least square fit between $\tau_{\mathrm{p} \lambda}$ and $\lambda$ in a $\log$-log scale. In general, a good agreement with equation 1 was obtained, with correlation coefficient $R>0.6$ in most of the cases. The slope of the linear regression line gives the value of $\alpha$, while $\beta$ is evaluated from the intercept. The monthly mean values of $\alpha$ and $\beta$ are shown in Fig.4, which clearly indicates the spectral dependence that changed with the months, $\alpha$ ranging from $\sim 0.8$ to 1.3 , with a mean value of $\sim 1.01 \pm 0.06$ for the measurement period. The monthly variation of $\beta$ follows nearly the opposite pattern of $\alpha$, indicating that the high aerosol loading is mainly due to coarse mode particles. 


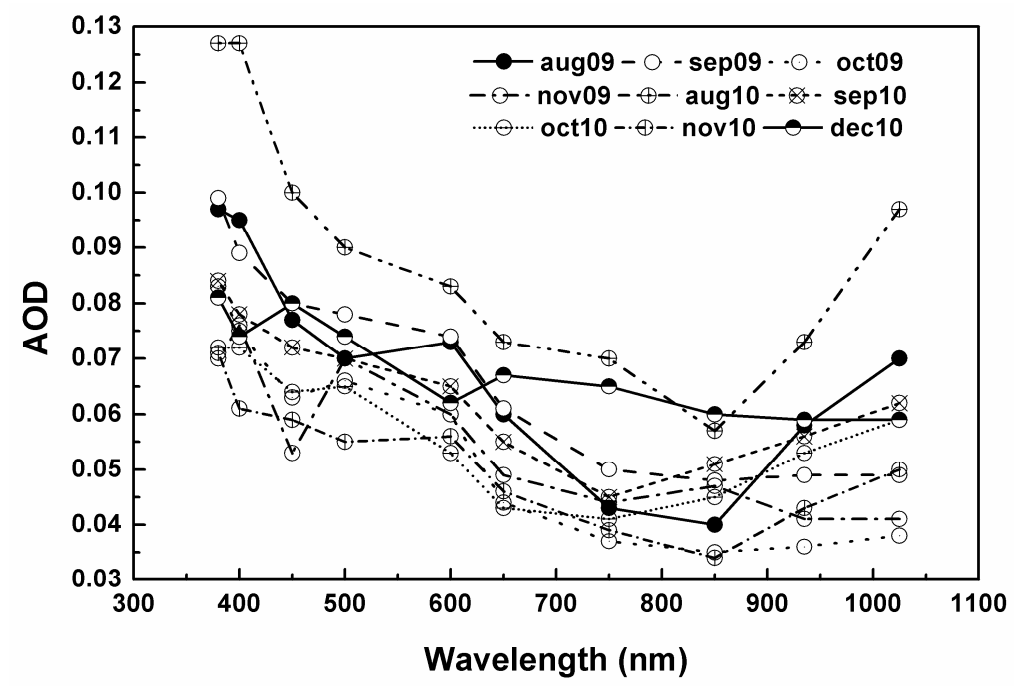

Figure 3: Spectral variation of monthly mean AOD during the measurement period

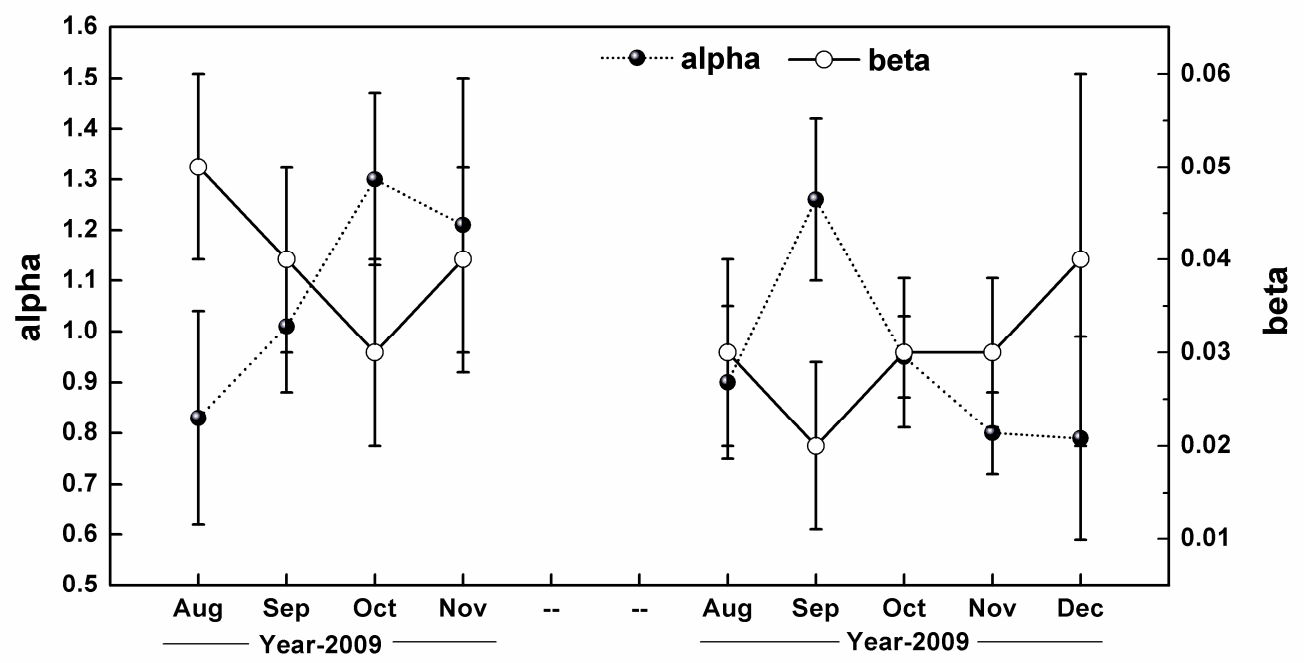

Figure 4: Temporal variation of monthly mean values of Angstrom exponent

Generally, the values of $\alpha \leq 1$ indicate aerosol size distributions dominated by coarse mode aerosols while the values of $\alpha \geq 2$ indicate aerosol columnar size distributions dominated by fine mode aerosols $(r<1 \mu \mathrm{m})$ such as those associated with biomass burning or urban pollution, while values in between 1 and 2 suggest significant contributions from both accumulation mode and coarse mode aerosols to the columnar AOD. The large change in the values of $\alpha$ thus implies that the dominance of fine or coarse mode aerosols over Hanle varied significantly at different seasons. 


\section{Acknowledgement}

This work is carried out under the ARFI Project of ISRO-GBP.

\section{REFERENCES}

[1] Gobbi G. P., Angelini F., Bonasoni P., Verza G. P., Marinoni A. and Barnaba F.: Sunphotometry of the 2006-2007 aerosol optical/ radiative properties at the Himalayan Nepal Climate Observatory - Pyramid (5079 m a.s.l.), Atmos. Chem. Phys. Discuss., 10, 1193-1220, doi:10.5194/acpd-10-1193-2010, 2010.

[2] Holben B.N., Tanr D., Smirnov A., Eck T.F., et al., An emerging ground- based aerosol climatology: aerosol optical depth from AERONET J. Geophys. Res. Atmos. 106, 12067-12097, 2001.

[3] Kuniyal J. C., Thakur A., Thakur H. K., Sharma S., Pant P., Rawat P. S. and Krishna Moorthy K., Aerosol optical depths at Mohal-Kullu in the northwestern Indian Himalayan high altitude station during ICARB, J. Earth Syst. Sci. 118 (1), , pp. 41-48, 2009.

[4] Marcq, S., Laj P., Roger J. C., Villani P., Sellegri K., Bonasoni P., Marinoni A., Cristofanelli P., Verza G. P. and Bergin M., Aerosol optical properties and radiative forcing in the high Himalaya based on measurements at the Nepal Climate ObservatoryPyramid site (5079ma.s.1.), Atmos. Chem. Phys., 10, 5859-5872, 2010.

[5] Moorthy K. K., Babu S. S., Satheesh S. K., Temporal heterogeneity in aerosol characteristics and the resulting radiative impact at a tropical coastal station-part 1: microphysical and optical properties, Annales Geophysicae, 25, 2293-2308, 2007.

[6] Sagar R., Kumar B., Dumka U. C., Moorthy K. K. and Pant P., Characteristics of Aerosol spectral optical depths over Manora peak: A high altitude station in the central Himalayas, J. Geophys. Res., 109, D06207, doi:10.1029/2003JD003954, 2004.

[7] Six D., Fily M., Blarel L., Goloub P., First aerosol optical thickness measurements at Dome C (East Antarctica), summer season 2003-2004 Atmos. Environ. 39, 5041-5050, 2005. 